Mundo Revista de agrario
Mundo Agrario, diciembre 2018, vol. 19, n 42, e099. ISSN 1515-5994

Universidad Nacional de La Plata

Facultad de Humanidades y Ciencias de la Educación

Centro de Historia Argentina y Americana

\title{
Propiedad intelectual en semillas: los dispositivos del cercamiento jurídico en Argentina
}

\section{Tamara Perelmuter}

Instituto de Investigaciones Gino Gemani, Instituto de Estudios de América Latina y el Caribe, Universidad de Buenos Aire, Argentina

tamiperelmuter@gmail.com

Cita sugerida: Perelmuter, T. (2018). Propiedad intelectual en semillas: los dispositivos del cercamiento jurídico en Argentina. Mundo Agrario, 19(42), e099. https://doi.org/10.24215/15155994e099

Recibido: 18 octubre 2017 - Aceptado: 21 agosto 2018 - Publicado: 07 diciembre 2018

cc)(1) Esta obra está bajo licencia Creative Commons Atribución-NoComercial-CompartirIgual 4.0 Internacional http://creativecommons.org/licenses/by-nc-sa/4.0/deed.es_AR 


\title{
Propiedad intelectual en semillas: los dispositivos del cercamiento jurídico en Argentina
}

\author{
Intellectual property in seeds: the devices of legal enclosure in Argentina \\ Tamara Perelmuter \\ Instituto de Investigaciones Gino Gemani, Instituto de \\ Estudios de América Latina y el Caribe, Universidad de \\ Buenos Aire, Argentina \\ tamiperelmuter@gmail.com
}

\section{Resumen:}

El objetivo de este artículo es examinar la forma en que se expresan los procesos de cercamiento jurídicoen torno a las semillas en Argentina. A partir de análisis bibliográfico, de legislación y de entrevistas a informates clave, se identifica una proliferación y complejización de dispositivos: la Ley de Semillas y los diversos intentos por modificarla; los intentos por patentar las semillas transgénicas; las disputas por el cobro de las regalías de la soja RR; los contratos bilaterales firmados por Monsanto y los productores en relación de la soja Intacta; y las resoluciones tendientes a recortar el uso propio de las semillas. Estos no se dieron de manera lineal y estuvieron atravesados por tensiones y conflictos. El tema sigue abierto y, por lo tanto, las semillas en Argentina son un elemento de importantes debates y múltiples disputas.

Palabras clave: Semillas, Cercamiento jurídico, Propiedad intelectual, Transgénicos, Soja.

\section{Abstract:}

The objective of this article is to examine the way in which legal enclosure processes are expressed around seeds in Argentina. From bibliographical analysis, legislation and interviews to key informants, a proliferation and complexity of devices is identified: the Law of Seeds and the various attempts to modify it; attempts to patent transgenic seeds; the disputes over the collection of the RR soybean royalties; the bilateral contracts signed by Monsanto and the producers in relation to the Intacta soybean; and the resolutions tending to reduce the own use of the seeds. These processes did not occur in a linear way and were crossed by tensions and conflicts. The problematic is still open and, therefore, the seeds in Argentina are an element of important debates and multiple disputes.

KEYWORDS: Seeds, Legal enclosure, Intellectual property, Transgenic, Soy.

\section{INTRODUCCIÓN}

El cercamiento de los commons, proceso que Marx (2000) describió como de acumulación originaria, consistió en el despojo de los comuneros de sus tierras y en su privatización. Autores recientes (Bonefeld, 2001; De Angelis, 2001; Perelman, 2001; Harvey, 2004; Roux, 2008) han puntualizado que la acumulación originaria no es sólo la etapa que dio origen al capitalismo, sino un proceso continuo y permanente de separación de los productores de sus medios de producción y de subsistencia. Esto ha sido denominado por David Harvey (2004) como acumulación por desposesión.

En los últimos años estamos asistiendo a una profundización de los procesos de cercamiento, mediante los cuales aquello que esencialmente era común y quedaba por fuera del mercado, se está convirtiendo rápidamente en una mercancía (Marx, 2000).

Las semillas no quedaron fuera, y el cercamiento de las mismas ocurre a partir de dos tipos de mecanismos articulados entre sí y que facilitan su apropiación: el cercamiento agrario, que remite las transformaciones en los modelos que acompañan los cambios técnicos de las semillas; y el cercamiento jurídico, donde la propiedad intelectual cumple un rol central. Esto conlleva una reconfiguración constante de la relación de los productores con sus semillas. 
En este artículo nos centraremos en el análisis del caso argentino dada su relevancia. Por un lado, se trató de un país pionero en América Latina en la protección mediante propiedad intelectual de las semillas con la sanción en 1973 de la Ley de Semillas y Creaciones Fitogenéticas. Por otro lado, adoptó tempranamente las semillas transgénicas (1996), lo que generó importantes transformaciones del modelo agroalimentario (Teubal, 2006), y de manera paralela las leyes que regulan la propiedad intelectual en semillas (Ley de semillas y Ley de patentes) fueron reformadas para la misma época. Finalmente, porque desde 2003 existen intentos por modificar nuevamente la Ley de Semillas, con la intención de brindarle mayores certidumbres económicas a las empresas y recortando derechos de los productores al uso propio de sus semillas. Durante 2012, esta discusión se intensificó. Por un lado, un anteproyecto elaborado desde el Ministerio de Economía comenzó ser a ser discutido en el marco de la CONASE (Comisión Nacional de Semillas). Por otro lado, el gobierno le aprobó a Monsanto la utilización de una nueva generación de semillas de soja denominada Intacta RR2 Pro, mientras que la empresa implementó contratos bilaterales con los productores que, entre otras cosas, los obligaba a pagar regalías extendidas. En 2016, luego del cambio de gobierno y de etapa política (EDI, 2016), varios proyectos para la modificación de la Ley de Semillas fueron presentados en el Congreso Nacional.

La intención de este artículo es analizar la forma en que se expresan los procesos de "cercamiento jurídico"en torno a las semillas en Argentina. Para su análisis identificamos una proliferación y complejización de cinco dispositivos: 1) la Ley de Semillas y los diversos intentos por modificarla; 2) los intentos por patentar las semillas transgénicas; 3 ) las disputas por el cobro de las regalías de la soja RR; 4) los contratos bilaterales firmados por Monsanto y los productores en relación de la soja Intacta RR2 Pro, y 5) las resoluciones tendientes a recortar el uso propio de las semillas.

Los interrogantes que acá se presentan fueron realizados a partir del estudio articulado entre fuentes secundarias y primarias. En relación a las primeras, se trató de análisis de bibliografía sobre la temática; de documentación oficial; de declaraciones de las organizaciones empresariales, de productores y sociales; de artículos periodísticos y de publicaciones en Internet ${ }^{1}$. Con fuentes primarias nos referimos a la realización de una serie de entrevistas a informantes clave, es decir, actores u observadores privilegiados de los procesos estudiados (representantes del Estado, de organizaciones de productores y de la sociedad civil). Asimismo, en este artículo utilizamos el análisis de la legislación argentina de propiedad intelectual en semillas elaborado en una publicación anterior (Perelmuter, 2017).

El tema aquí estudiado sigue abierto y por lo tanto, las semillas en Argentina son un elemento de importantes debates y múltiples disputas.

\section{El Cercamiento de las Semillas}

Desde el nacimiento de la agricultura hasta no hace mucho tiempo, el proceso de selección y mejora estuvo en manos de los agricultores, quienes recurrentemente guardaron e intercambiaron sus semillas con otros productores.

A diferencia de otros productos, la semilla es un ser vivo que puede reproducirse y es por esto que ha sido difícil transformarlas en una mercancía. Pero el capital buscó siempre estrategias diversas para sortear las barreras derivadas del carácter natural de la agricultura (Bartra, 2008). De esta manera, a través del avance de las formas capitalistas, el agro fue transformándose progresivamente en una actividad en la cual los elementos necesarios para efectuar la producción se obtienen en el mercado (semillas, maquinaria, productos químicos y trabajo asalariado), y provienen de otros sectores de actividad, mayoritariamente la industria, así como de distintos territorios (Bianco, 2015).

Hasta el advenimiento de la ciencia genética y la investigación sistemática en mejoramiento vegetal, los agricultores eran quienes, con base en un conocimiento empírico, seleccionaban las mejores semillas para su posterior siembra y producían sus propias semillas mediante la técnica de cruzamiento. Pero con la aparición 
de las semillas híbridas primero, y la expansión de las biotecnologías aplicadas al agro luego, se produjeron grandes cambios en las estrategias de privatización del conocimiento, el uso y la reproducción de semillas, que habilitan nuevos mecanismos de acumulación de capital. Y por lo tanto, las semillas se volvieron un punto de interés estratégico en el desarrollo de la agricultura capitalista (Kloppenburg, 2005).

En ese sentido, los nuevos procesos decercamiento, como mencionamos, tienen su expresión particular en el caso de las semillas articulando dos procesos.

Una primera forma es el cercamiento agrario y se da a partir de las transformaciones en el modelo agrario que acompañan los cambios técnicos de las mismas. En este sentido, se analiza la aparición de las semillas híbridas en el marco de la Revolución Verde primero, y el desarrollo de las semillas transgénicas en el marco de la consolidación del modelo biotecnológico agrario (López Monja, Poth y Perelmuter, 2010).

La segunda forma es el cercamiento jurídico que, en articulación con lo anterior, aparece con los cambios en las formas de apropiación de las semillas. Ésta se da mediante las leyes de semillas, que exigen el obligatorio registro y certificación; a través de los contratos que realizan las empresas con los productores, y, sobre todo, a partir de las legislaciones de propiedad intelectual. Esto implica, a su vez, una reconfiguración constante de la relación de los productores con sus semillas.

En el caso específico de las semillas, hay dos formas de reconocer su propiedad intelectual. Por un lado, los derechos de obtentor (DOV), que son otorgados a quienes producen variedades mejoradas de semillas agrícolas para explotarla en exclusividad, pero no alcanzan al producto obtenido. Por otro lado, las patentes de invención, que son derechos exclusivos otorgados por el Estado a una invención, es decir, a un producto o procedimiento que aporta una nueva manera de hacer algo. En el caso específico de las semillas, la protección involucra al producto y las sucesivas generaciones del vegetal. Esto a su vez, impide la utilización de la semilla en la nueva siembra por el agricultor sin el correspondiente pago de regalías. Vale aclarar que sólo pueden ser objeto de protección las invenciones, no así los descubrimientos ${ }^{2}$.

Hasta los años sesenta, los materiales vegetales utilizados para el mejoramiento genético eran de libre acceso. Este principio comenzó a resquebrajarse cuando la regulación en torno a la protección de derechos de obtentor a nivel internacional se institucionalizó en 1961 con el nacimiento de la UPOV (Unión para la Protección de Obtenciones Vegetales), convención que fue modificada en tres oportunidades: 1972, 1978 y 1991.

La versión 78 de UPOV contempla implícitamente el derecho de los agricultores ${ }^{3}$. Esto implica que los agricultores, a excepción de su venta comercial, conservan el derecho a producir libremente sus semillas y pueden utilizar el producto de la cosecha que hayan obtenido por el cultivo en su propia finca. Es lo que se conoce como el uso propio de las semillas.

Hasta los años ochenta las patentes sobre organismos vivos no estaban permitidas. Sin embargo, el fallo Diamond-Chakrabarty de la Corte Suprema de Estados Unidos, que admitió una patente sobre una bacteria modificada capaz de separar los componentes de petróleo crudo, constituyó una bisagra al delimitar lo que es patentable y lo que no. La decisión radicó en considerar a la bacteria en cuestión como una manufactura, ya que su existencia se debía a una manipulación genética, en decir, a una invención del hombre. De esta manera, se ha abierto un nuevo e inmenso campo para la propiedad intelectual desconocido anteriormente: la propiedad intelectual sobre formas de vida (Bartra, 2008).

A partir de los años 90, empresas transnacionales semilleras y biotecnológicas vienen presionando con gran intensidad para lograr una armonización internacional de la legislación de propiedad intelectual. Por un lado, ante las fuertes presiones para lograr una mayor protección a la biotecnología, UPOV se reformuló en 1991 recortando las excepciones del acta de 1978, que otorgaba algunos derechos a los nuevos fitomejoradores y a los agricultores.

Por otro lado, a partir de mediados de los años noventa, las transformaciones más profundas en relación a la propiedad intelectual comenzaron a realizarse a través de la Organización Mundial del Comercio (OMC). Uno de los principales acuerdos introducidos en 1995, en el marco de la OMC, fue sobre los Aspectos 
de los Derechos de Propiedad Intelectual que afectan al Comercio (ADPIC), que surgió como uno de los principales pilares de la Ronda de Uruguay. En relación con las patentes, el acuerdo representa una clara profundización en los intentos de apropiación ya que amplía el alcance de lo que se considera patentable.

\section{Los dispositivos del CERCAMIENTo JURÍdico en Argentina}

A partir de la realización de una crónica del cercamiento de las semillasen términos históricos, en una publicación anterior (Perelmuter, 2017) identificamos tres etapas; cada una de ellas finaliza con algún acontecimiento importante en relación al cercamiento de las semillas que funciona como bisagra entre una y otra.

Una primera etapa a la que denominamos La Argentina como pionera (1973 - 1991) vincula la sanción de la Ley de Semillas y Creaciones Fitogenéticas del año 1973 con la Revolución Verde en este país ${ }^{4}$.

La segunda etapa fue nombrada La biotecnología agraria entra en escena (1991-2003). Durante este periodo, se configuró lo que denominamos modelo biotecnológico agrario (López Monja, Poth y Perelmuter, 2010), a partir de algunos acontecimientos claves: el Decreto de Desregulación (1991), que llevó a la desarticulación del andamiaje legal e institucional que regulaba la producción agropecuaria; la creación de la CONABIA (Comisión Nacional de Biotecnología Agropecuaria) en 1991, y la aprobación de la soja RR (1996). Asimismo, esto coincidió con la modificación del Reglamento de la Ley de Semillas y Creaciones Fitogenéticas a partir del Decreto 2183/91 y con la sanción de la Resolución “35/96” (dictada por INASE) en 1996.

La tercera etapa, El uso propio en debate (2003 - 2015), es la consolidación del modelo analizado en el periodo anterior y el comienzo de un debate en torno al uso propio de las semillas y a la posible reforma de la Ley de Semillas. El período se caracteriza por la activa sanción por parte del Estado de leyes y regulaciones, pero se define aún más a partir de nuevas estrategias de legitimación del mismo, aportando a lo que varios autores denominaron como la consolidación de un nuevo consenso (Svampa, 2012).

Finalmente, es necesario incorporar una nueva etapa que se inició en 2016 con la asunción del gobierno de Cambiemos, y que implicó un cambio de etapa política (EDI, 2016) a la que denominaremos Los agronegocios en tiempos de Macri. Desde su asunción, el nuevo gobierno tomó múltiples medidas que marcaron una profundización de los agronegocios ${ }^{5}$, y el debate por el cercamiento jurídico de las semillas se intensificó.

En este artículo vamos a tomar un camino diferente ya que va a estar estructurado en torno a cinco dispositivos de cercamiento jurídico que se desplegaron con intensidades diferentes a lo largo de cada periodo: 1) la Ley de Semillas y los diversos intentos por modificarla; 2) los intentos por patentar las semillas transgénicas; 3) las disputas por el cobro de las regalías de la soja RR; 4) los contratos bilaterales firmados por Monsanto y los productores en torno a la soja Intacta RR2 Pro, y 5) las resoluciones tendientes a recortar el uso propio de las semillas.

\section{La Ley de Semillas}

Las leyes de semillasfueron creadas durante la Revolución verde con el objetivo de "ordenar" los mercados de semillas (Grain, 2005). En términos generales, las normas allí plasmadas refieren a todo aquello que los agricultores no pueden hacer, ya que dictaminan cuáles son las semillas que no pueden venderse, intercambiarse y hasta usarse. Por un lado, establecen estrictas normas de certificación imponiendo una producción y reproducción de las semillas controladas por el aparato público ${ }^{6}$. Por otro lado, ejercen un fuerte control del ingreso de nuevas variedades al mercado formal, que, a su vez, deben cumplir una serie de requisitos agronómicos. De esta manera, bajo la aplicación estricta de las leyes sobre semillas -que obliga a los agricultores a utilizar solo semillas registradas o certificadas- actividades que históricamente fueron 
parte constitutiva de los sistemas de semillas diversificados como el mejoramiento vegetal participativo o la organización de ferias de semillas para compartir e intercambiar variedades locales, comenzaron a tornarse ilícitas (Shiva, 2003).

El caso argentino es particular, ya que, como veremos, la Ley de Semillas articula estos elementos con la protección de las semillas mediante una forma de propiedad intelectual: el derecho de obtentor (DOV).

La historia comienza a principios de los años setenta, cuando el desarrollo de la agricultura local enmarcada en la Revolución Verde, sumado a la influencia de los cambios que se venían produciendo en los países del Norte respecto de los derechos de propiedad sobre variedades de plantas ${ }^{7}$, fue allanando el camino para la aparición de un debate que planteara la necesidad de modernizar la legislación vigente, que era considerada insuficiente ${ }^{8}$ (Gutiérrez, 1994).

La Ley de Semillas y Creaciones Fitogenéticas No 20.247 fue promulgada el 30 de marzo de $1973^{9}$, al tiempo que se creó la Comisión Nacional de Semillas (CONASE). La regulación recién se realizó en 1978 con la sanción del Decreto $\mathrm{N}^{\circ} 1995$ que la reglamentaba. Ese mismo año, se creó el Servicio Nacional de Semillas (SENASE) como órgano de aplicación y, dentro de éste, se crearon los distintos registros.

En el momento de discusión y elaboración de la ley surgió el interrogante de si se debían preparar dos proyectos de ley separados. Por un lado, una ley de semillas clásica, que regulara la producción, la certificación y la comercialización de todas las semillas del país. Por otro lado, una legislación para la protección de la propiedad de los cultivares. Sin embargo, se decidió incorporar en el mismo cuerpo legal ambas cosas. Por lo tanto, se trató de una herramienta legal de gran alcance ya que reunió las exigencias para la producción y el comercio de semillas, y la protección de la propiedad de las nuevas creaciones fitogenéticas. De esta manera, y a diferencia de lo que ocurrió en la gran mayoría de los países latinoamericanos, fue posible proteger con derechos de propiedad intelectual las variedades vegetales muy tempranamente ${ }^{10}$.

La UPOV, hasta su versión de 1978, como vimos, contempla excepciones importantes. Y si bien la ley argentina es de 1973, ésta ya reflejaba estas excepciones que ya estaban en UPOV 61, aun cuando Argentina recién adhirió al tratado internacional en 1994.

En ese sentido, el derecho (excepción) de los agricultores quedó reflejado en el artículo $\mathrm{N}^{\circ} 27$ en el que se especifica que,

No lesiona el derecho de propiedad sobre un cultivar quien entrega a cualquier título semilla del mismo mediando autorización del propietario, o quien reserva y siembra semilla para su propio uso, o usa o vende como materia prima o alimento el producto obtenido del cultivo de tal creación Fitogenética (Ley de Semillas y Creaciones Fitogenéticas Na 20.247, Art. 27).

Durante los años 90, el debate en torno a la Ley de Semillas tomará un nuevo impulso. En 1990 se conformó la Asociación Argentina de Protección de Obtenciones Vegetales (ARPOV) ${ }^{11}$. En 1991 tuvo lugar la última modificación existente al Reglamento de la Ley de Semillas y Creaciones Fitogenéticas (Ley 20.247), que incorporó algunos principios contenidos en el Convenio de la Unión Internacional para la Protección de las Obtenciones Vegetales (UPOV).

Una de las principales razones para la sanción del decreto que modificó el reglamento, fue la fuerte presión política ejercida por las asociaciones de productores de semillas, como el ASA y ARPOV y otros grupos de interés dentro de CONASE (Filomeno, 2012). Se trataba, tal como remarca con claridad Regúnaga (2013), de reforzar aún más el peso del sector privado ${ }^{12}$.

Por su parte, Vicente (2013) hace eje en la idea de paquete para analizar la articulación entre la creación de la CONABIA, la aprobación de la soja transgénica y el reforzamiento del marco regulatorio. Por lo tanto, la sanción del decreto que modificó el Reglamento fue parte de la misma estrategia, orientada a reforzar los derechos de propiedad intelectual aplicados a variedades vegetales, y respecto a la cual confluyó otro acontecimiento: la adhesión de Argentina a UPOV 78 en 1994 a través de la Ley $24.376^{13}$. 
Según Gutiérrez (1994), la decisión de Argentina a adherir a UPOV fue resultado de un paulatino proceso de convencimiento emprendido por diversos actores que habían comenzado a vincularse externamente con firmas que querían establecer programas de multiplicación de sus variedades en Argentina ${ }^{14}$. Para comienzos de los noventa, el hecho de tener una legislación considerada moderna e inspirada en UPOV pero sin estar adheridos al convenio generaba cierta desconfianza y falta de credibilidad en el sistema de protección de la propiedad nacional. Ahora bien, la decisión de adherir a la versión 78, y no la de 1991, que ya se encontraba vigente, para Regúnaga (2013) se trató simplemente de una cuestión de fechas: cuando se inician los trámites en el año $1991^{15}$ estaba vigente la versión 78 .

Un elemento importante a destacar de la reforma del Reglamento de la Ley de Semillas es que no se tocaron las excepciones. Por lo tanto, reafirma el derecho de los productores a guardar y replantar semillas de sus propios campos para uso propio sin el consentimiento de los propietarios de los cultivares. Para Regúnaga (2013), secretario de Agricultura y encargado de impulsar dicha reforma, no había cuestionamientos hacia el uso propio,

(...) yo creo que el problema del uso propio es un problema que aparece en las demandas del sector privado unos diez años después y en todo caso, a lo mejor por el problema quizás no tanto el uso propio como de la ineficiencia que tuvo el INASE, que se desfinanció y que dejó de controlar, y que en definitiva el problema no es o no fue durante la década del noventa que se permitía el uso propio, sino el de la bolsa blanca ${ }^{16}$ como reventa de semillas no. Que va mucho más allá que el uso propio.

Por lo tanto, esta situación se mantuvo así hasta finales de 2003, cuando la SAGPyA comenzó a presentar dentro de CONASE una serie de propuestas para modificar la Ley de Semillas que implicaban de manera implícita o explícita, la adhesión de la Argentina a UPOV 91. El punto principal de las reformas tenía que ver con restringir el derecho de los productores rurales para guardar semillas determinando el pago de regalías por las mismas (Casella, 2005). Se trató, de esta manera, de la respuesta brindada por las autoridades estatales a las demandas que cada vez más fuertes de las empresas de semillas.

En 2007 los intentos por modificar la Ley de Semillas y Creaciones Fitogenéticas se reanudaron. El proyecto base sobre el cual se estuvo trabajando fue elaborado por el Centro de Propiedad Intelectual de la Universidad Austral y coordinado por Miguel Ángel Rapela, expresidente de ASA y ARPOV. El dato más llamativo de esta propuesta es que, a diferencia de la Ley vigente y del resto de las propuestas de modificación, trataba únicamente de la protección del derecho de obtentor. El conflicto en torno a la Resolución 125 que se inició en 2008, hizo que el debate quedara momentáneamente frenado.

El año 2012 va a ser crucial ya que comienza un nuevo período con el anuncio del gobierno de dos grandes decisiones. En primer lugar, la empresa Monsanto presentó junto al por entonces ministro de Agricultura, Ganadería y Pesca de la Nación, Norberto Yauhar, la nueva tecnología en soja Intacta RR2 Pro, que fue modificada genéticamente por Monsanto para lograr un cultivo que, como su antecesor, será resistente al glifosato (el más popular herbicida) y le agregará resistencia al ataque de insectos.

Y finalmente, en tercer lugar, el ministro anunció que desde el gobierno nacional se estaba trabajando en una nueva ley de semillas para reforzar los derechos de propiedad intelectual de biotecnología agrícola. Con este fin, se abrió una mesa de negociaciones en el marco de la CONASE (Comisión Nacional de Semillas), de la que participaron miembros de organismos públicos ${ }^{17}$, del sector privado ${ }^{18}$ y de las entidades de productores agrarios ${ }^{19}$. Cabe destacar que otros actores vinculados a las semillas, como las organizaciones campesinas e indígenas, o aquellas relacionadas con la denominada agricultura familiar, no fueron consultados ni incorporados formalmente al debate ${ }^{20}$.

Según se pudo consignar ${ }^{21}$, al igual que la versión actualmente vigente, dicha versión seguía condensando en un mismo cuerpo legal todo lo referido a producción, certificación y comercialización de semillas, por un lado, y la protección de la propiedad intelectual en semillas, por el otro.

Sin hacerlo explícito, estas versiones tomaban algunos elementos de UPOV 91. Por lo tanto, una de las consecuencias más importantes tenía que ver con el impacto directo en los derechos de los productores 
agrarios a guardar, conservar, intercambiar y reproducir sus propias semillas, ya que la nueva legislación apuntaba a reglamentar y restringir el uso propioy remarcaba que sólo podrán hacer uso de esta prerrogativa los denominados agricultores exceptuados ${ }^{22}$.

El proyecto oficial no logró salir de la Comisión Nacional de Semillas (CONASE) y, para fines de 2012, las negociaciones se estancaron. Ningún proyecto oficial entró al Congreso y los presentados por las bancadas opositoras nunca fueron discutidos.

En el mes de mayo de 2014, se presentó un nuevo ante proyecto de ley de semillas y creaciones fitogenéticas, en el marco de unas jornadas de las que participaron varias organizaciones campesinas y de pequeños productores de todo el país. Respecto de las versiones anteriores, el nuevo borrador incorporaba artículos en relación a las especies nativas y criollas, agricultura familiar y pueblos originarios, y su vínculo con el resto de la Ley. Ésta consistía en un "extenso articulado donde se pretendían congeniar intereses contrapuestos, siguiendo la premisa de la posible coexistencia entre agronegocio capitalista y agricultura familiar" (Trivi, 2016, p. 67).

Luego de varios años en que se discutía la posibilidad de modificar la Ley de Semillas pero no se presentaba de manera formal ningún ante proyecto, en octubre de 2016 el gobierno de Macri, luego de varios meses de negociaciones en secreto, presentó su propuesta. $\mathrm{Al}$ igual que el resto de los anteproyectos que analizamos, acota la figura del uso propio ${ }^{23}$. Algunos sectores de la oposición política también presentaron proyectos. Pero la gran novedad fue la presentación de propuestas por parte de una entidad de productores (FAA) y una cámara empresarial (ASA). Este último anteproyecto avanzaba mucho más en el recorte del uso propio que el proyecto del oficialismo, al no plantear siquiera excepciones.

Si bien hubo algunas reuniones de la comisión de agricultura para la discusión del tema, no hubo acuerdos y, por lo tanto, los proyectos perdieron estado parlamentario y sigue sin resolverse la modificación de la Ley de Semillas. Sin embargo, el gobierno trabaja a contrarreloj y aún sin éxito en lograr un proyecto de "consenso" entre las empresas y las entidades agropecuarias.

Más allá de las diferencias entre todos los proyectos existentes desde 2003 (presentados formalmente o no), el debate siempre estuvo orientado a discutir la distribución de la renta agraria entre los diversos sujetos involucrados. Y, como vimos, el punto fuerte del debate se centró en la figura de uso propio, y todo lo que gira en torno a eso: pago/cobro de regalías; debate entre legalidad/ilegalidad; penalizaciones y criminalización.

\section{La (no) patente de Monsanto}

El segundo dispositivo está relacionado con otra de las formas de propiedad intelectual que "protegen" a las semillas: las patentes de invención.

En mayo de 1995, tras un complejo proceso legislativo, se aprobó la Ley de Patentes y Modelos de Utilidad $\mathrm{N}^{\circ} 24.481$ en reemplazo de la ley $\mathrm{N}^{\circ} 111$, que regía en el país desde $1864^{24}$. El debate de esta nueva legislación estuvo atravesado por el lobby ejercido por las empresas farmacéuticas, más que las semilleras y biotecnológicas (Bergallo y Ramón Michel, 2012).

La reforma constituyó una respuesta temprana a la aprobación, en abril de 1994, del ADPIC. En términos del tema que nos ocupa -el cercamiento de las semillas-, para la legislación argentina los descubrimientos no son considerados invenciones, y por lo tanto, no son patentables. Al respecto, contiene una lista de actos o creaciones humanas que no son considerados una invención patentable. Y en el inciso $g$ ) explicita que "No son consideradas invenciones (...) Toda clase de materia viva y sustancias preexistentes en la naturaleza" (Art. No6). Tal como remarca Díaz Ronner (2013), esta disposición es inclusiva de los microorganismos en el estado de su existencia en la naturaleza. 
Asimismo, define las "excepciones de patentabilidad", ya sea porque no son consideradas invenciones, o porque, aun si reúnen los requisitos positivos que describimos previamente, no son patentables. El mismo establece que:

No son patentables: a) Las invenciones cuya explotación en el territorio de la República Argentina deba impedirse para proteger el orden público o la moralidad, la salud o la vida de las personas o de los animales o para preservar los vegetales o evitar daños graves al medio ambiente; b) La totalidad del material biológico y genético existente en la naturaleza o su réplica, en los procesos biológicos implícitos en la reproducción animal, vegetal y humana, incluidos los procesos genéticos relativos al material capaz de conducir su propia duplicación en condiciones normales y libres tal como ocurre en la naturaleza (Ley de Patentes, Art. No 7 ).

El proyecto original debatido en el Congreso contenía en el art. 7 sobre exclusión de patentabilidad tres incisos, dos de los cuales, $b$ ) y $c$ ), hacían referencia expresa a las innovaciones biotecnológicas. Pero el Poder Ejecutivo vetó varios artículos, entre ellos, el inciso $c$ ) por lo que resultó excluida la cláusula que se refería a la exclusión de patentabilidad de las plantas, animales y procesos esencialmente biológicos para su reproducción. Sin embargo, para salvar el vacío, el decreto reglamentario volvió a incluir esta exclusión en el Art.6 estableciendo que "No se considerará materia patentable a las plantas, los animales y los procedimientos esencialmente biológicos que conducen a su reproducción”.

De todo lo expuesto, se infiere que según la Ley de Patentes y Modelos de Utilidad N² 24.481 no son patentables los animales, las plantas y los procesos genéticos que conducen a los organismos vivos a su propia duplicación o reproducción. Tampoco lo son los microorganismos que son aislados, caracterizados y purificados, pues estas actividades no constituyen actividad técnica suficiente para conferir altura inventiva 25 (Díaz Ronner y Folgueras, 2017).

No obstante, sí se admite el patentamiento de microorganismos nuevos obtenidos artificialmente por vía de la ingeniería genética. Por lo tanto, integran la materia viva patentable aquellos microorganismos, hibridomas y anticuerpos monoclonales, cortes de nucleótidos, proteínas, siempre que cumplan con los requisitos de novedad, altura inventiva y aplicación industrial, y en tanto y en cuanto sean modificados y diferentes a los que se encuentran en la naturaleza.

A pesar de ello, en febrero de 1996 la empresa Monsanto presentó ante el Instituto Nacional de la Propiedad Industrial (INPI) -organismo estatal encargado de registrar las patentes- una solicitud de patente por la cual reivindicaba (según consiga la propia empresa) tres inventos: a) un método para producir una planta transgénica; b) moléculas de ADN recombinante de doble cadena que habrían de ser incorporadas a las plantas para su transformación, y c) células vegetales modificadas por tales moléculas. La solicitud fue rechazada por improcedente, dado que la Ley de Patentes considera que la molécula de ADN recombinante y las células modificadas no constituyen una invención, porque son materia viva y preexistente en la naturaleza, o bien, "material biológico y genético o su réplica" (Naturaleza de Derechos, 2016).

La empresa apeló y en 2007, un juez de primera instancia dio la razón a Monsanto. El organismo oficial recurrió a la segunda instancia judicial, la cual falló de manera inédita rechazando que la multinacional pudiera patentar como propias las moléculas de ADN y las células vegetales. La empresa apeló el fallo (fechado el 26 noviembre de 2015) y actualmente la estrategia apunta a que la Corte Suprema de Justicia se exprese a su favor. Mientras tanto, organizaciones sociales y referentes socioambientales de la Argentina y del mundo solicitaron al máximo tribunal de la nación que someta ese proceso judicial a una instancia de audiencia pública y amigos del tribunal.

Por su parte, el gobierno de Mauricio Macri designó como funcionario a cargo de la vicepresidencia del Instituto Nacional de la Propiedad Industrial INPI, a José Alfredo Martínez de Hoz (h), quien acompañará a Dámaso Alejandro Pardo. Ambos son socios y representantes legales de un estudio jurídico que asesora a las principales empresas transnacionales en el país en asuntos jurídicos y propiedad intelectual. 
Por lo tanto, todo indica que tanto el intento por revertir la disposición que le niega a Monsanto su patente como las presiones por modificar la Ley de Patentes - para que no existan dudas de que todo el material biológico puede ser patentado- serán parte de la estrategia del gobierno en los próximos años.

\section{IIII. Disputa por las regalías de la soja RR}

El tercer dispositivo estuvo centrado en la disputa en torno al cobro de regalías. Éstas son entendidas como la compensación que se le paga a quien posee algún título de propiedad intelectual, ya sea que se trate de un derecho de obtentor o una patente. Cabe destacar que en el ejercicio del monopolio concedido por los derechos de propiedad intelectual, las empresas semilleras desarrollan una tendencia a explotar el mercado al cobrar precios más elevados ${ }^{26}$.

En el año 1996, la Secretaría de Agricultura, Ganadería, Pesca y Alimentos (SAGPyA) le otorgó la licencia a Monsanto para comercializar la soja RR (Roundup Ready) junto al glifosato, herbicida al cual el cultivo es resistente, mediante la resolución No 167/1196 de SAGPyA. Se trató de la incorporación de insumos relativamente baratos (semillas y herbicidas), especialmente porque no incluía pago alguno en concepto de regalías por el uso del gen RR, ya que Monsanto en Argentina no obtuvo la patente (Pellegrini, 2013). La innovación de esta semilla fue difundida en este país sobre todo, por empresas con gran arraigo local, que obtuvieron la licencia de Monsanto, como Nidera (Campi, 2013).

El hecho de que Monsanto no hubiera patentado el gen Roundup Ready de la soja hizo que la difusión del gen RR se diera de manera vertiginosa, y que se convirtiera en el punto de partida para su difusión en América del Sur ${ }^{27}$. Y con una ventaja importante para la empresa: ella vendía también el herbicida (glifosato) al que la planta de soja se hace resistente. De este modo se pudo beneficiar con las ventas de sus semillas transgénicas y con las de crecientes volúmenes de glifosato. En el año 2000 la patente sobre el agroquímico en cuestión se venció y otras empresas comenzaron a producirlo. Con el cultivo de soja transgénica impuesto en Argentina y en plena expansión en toda la región, Monsanto comenzó a amenazar a los productores agrícolas sobre el supuesto uso "ilegal" de su semilla.

En 2004, el gobierno argentino rechazó estos reclamos y permitió que el glifosato chino siga en el mercado local (Arza, 2014) y el accionar de la empresa se volvió más agresivo aún. De esta manera, Monsanto comenzó a ejercer intimidaciones a los productores por el supuesto uso ilegal de las semillas, y amenazó con salirse del mercado argentino para intentar cobrar regalías en los puertos de destino de exportación de la soja de aquellos países donde sí tienen la patente. En 2005, la empresa consiguió frenar la entrada de buques con granos de soja y derivados provenientes de Argentina (Teubal 2006; Correa 2004; Pellegrini, 2013).

Ante esta situación, el gobierno argentino intervino en el conflicto como tercero interesado en las demandas que realizaba Monsanto en Europa (Pellegrini, 2013; Correa, 2009), argumentando que la patente que tiene la empresa en la Unión Europea rige sólo para la semilla transgénica y no en los subproductos sobre los que radica el reclamo (Martinolich, 2006). Por lo tanto, la posición del gobierno argentino se centró en calificar de extorsiva la conducta de Monsanto, argumentando que las demandas a los importadores, aun tratándose de un conflicto entre privados, tenía el fin de provocar una traba injustificada al comercio legítimo de harina de soja argentina. Finalmente, la Suprema Corte de Justicia de la Unión Europea dictaminó en 2010 a favor de la Argentina, a través de un fallo que sostenía que la compañía "no puede prohibir" la comercialización en Europa de la harina de soja argentina, que contiene, en estado residual, una secuencia de ADN patentada por la empresa estadounidense en algunos países de Europa, pero no en Argentina (Premici, 2010).

Asimismo, y contemporáneamente a los reclamos de Monsanto por la patente del gen de la soja RR, la discusión sobre las regalías pasó por varios tamices. Por un lado, desde 2003 la Asociación Argentina de Protección de las Obtenciones Vegetales (ARPOV) intenta legalizar el cobro permanente por el uso de las 
semillas mediante una modalidad de comercialización denominada regalía extendida. Mediante la misma, se busca que la regalía propia del licenciamiento para la producción y comercialización de semillas se extienda también a las sucesivas siembras que el agricultor realice con semillas de su propia cosecha.

Lo más destacable de esta modalidad es que el productor agrícola es obligado a pagar por el uso del material derivado del originariamente adquirido, en la medida en que lo vuelva a sembrar en su explotación. De esta manera, y dado que el agricultor no necesita de la autorización del obtentor para efectuar reserva de su propia semilla, podemos decir que -aun dentro del sistema de regalía extendida-sigue siendo libre. Pero deja de ser gratuito. Se altera así el régimen de la excepción del agricultor que permite el uso propio en forma gratuita.

El sistema generó grandes controversias, entre otras cosas, debido a que se trata de contratos de índole privada. Estos contratos incluyen una cláusula que autoriza ARPOV a enviar inspectores para verificar la ausencia de la reproducción ilegal, el uso y la comercialización de semillas en campos y lugares de acopio. Para las organizaciones de productores, en tanto, el derecho a guardar semillas (y la ley de semillas en su totalidad) es de orden público y, por tanto, no puede ser objeto de renuncia por un productor individual rural en un contrato privado (Filomeno, 2012). Esta discusión va a ser central cuando analicemos el dispositivo siguiente.

Por otro lado, en 2004, la Secretaría de Agricultura, Ganadería, Pesca y Alimentos (SAGPyA) presentó una propuesta de elaboración de una regalía globalo Fondo Fiduciario de Compensación Tecnológica e Incentivo a la Producción de Semillas, conformada por una tasa a la venta de cosecha destinada a compensar a los obtentores 28.

Se proyectaba que dicho fondo actuara en el ámbito del INASE y fuera administrado por una comisión integrada por representantes de los obtentores, de los usuarios y del organismo de la SAGPYA. Se conformaba con los ingresos provenientes de la aplicación de una tasa inferior al $1 \%$ sobre el precio de la primera venta del grano de la especie que se considere, la cual en una primera etapa abarcará al trigo y la soja.

Para Casella (2005), el rol que cumplía el Estado en esta iniciativa tenía como finalidad

(...) satisfacer las demandas de los titulares y las empresas de biotecnología y semillas (...). La impresión es que, dejando dudas sobre la legitimidad de esta alternativa, el Estado sustituye a los titulares y a las empresas en el ejercicio de sus derechos y se convierte en agente de intereses privados, sin siquiera costo alguno (...).

Debido al rechazo que tuvo por parte de la mayoría de los actores vinculados al mercado de las semillas, la propuesta de regalías globales no avanzó y nunca fue presentada formalmente al Congreso.

\section{Contratos soja RR2 Intacta}

Los contratos, el cuatro dispositivo decercamiento jurídico, fueron desarrollados para asegurar un control casi total de la cadena de producción agrícola y son firmados de manera bilateral entre las grandes empresas y los productores. Muchas veces, a través de ellos, las empresas consiguen privilegios mayores que los que le otorga la ley.

Como ya analizamos anteriormente, el Estado argentino fue a juicio internacional con la empresa Monsanto por las disputas en torno a las regalías de la soja Roundup Ready. En 2010, la Suprema Corte de Justicia de la Unión Europea dictaminó a favor de la Argentina.

Para entonces, la compañía ya había desistido de presionar a los importadores europeos, tal como hizo previo a la disputa con el Estado, pero comenzó a presionar por otros medios. En ese sentido, decidió no lanzar en el país su nueva soja transgénica, la Intacta RR2 Pro, a la espera de que se modificase el régimen legal en la Argentina, y así poder cobrar mayores regalías. En 2012 el escenario parecía haberse modificado. La misma fue aprobada bajo la resolución $446 / 12^{29}$ y comenzó a estar disponible en la campaña 2013/14. La empresa implementó contratos bilaterales con los productores que, entre otras cosas, los obligan a pagar regalías extendidas de por vida, a permitir el ingreso a su campo a fiscalizadores designados por la empresa, y a vender su cosecha únicamente a exportadores y/o acopiadores autorizados por Monsanto. Estos contratos 
van más allá de lo permitido por la legislación de semillas vigente, ya que contienen cláusulas absolutamente abusivas, y que, además, están en sintonía con las directivas de UPOV 91, que limitan el uso propio de las semillas a los agricultores.

Ese mismo año, Monsanto fue denunciado ante la Comisión Nacional de Defensa de la Competencia (CNDC) por la Federación de Cooperativas Federadas (FECOFE), la Cámara Argentina de Semilleros Multiplicadores (CASEM) y la Federación Argentina de Ingeniería Agronómica y productores agropecuarios por abuso de posición dominante. En la misma consta que:

Monsanto ha diseñado un nuevo modelo de negocios a través de un sistema de producción y comercialización para una nueva especie de soja (Intacta) que impone condiciones restrictivas a la competencia en su comercialización, procesamiento y acopio, asignando funciones y tareas de fiscalización y retención a determinadas empresas semilleras, las que deben reputarse como claramente abusivas.

El gobierno de Cambiemos ganó las elecciones con el apoyo más o menos explícito de sectores de productores, que incluían a las organizaciones que componían la Mesa de Enlace ${ }^{30}$. Por lo tanto, mediar y resolver este conflicto parece ser una prioridad importante. En ese sentido, a mediados de 2016 estableció mediante la resolución 107/06 el sistema BolsaTech, patrocinado por la Bolsa de Cereales de Buenos Aires, que consiste en establecer la "trazabilidad" de la información que se utiliza para los controles ${ }^{31}$. De esta manera, el Estado se hace cargo de controlar el origen de las semillas, en defensa de los intereses de los llamados “obtentores". La norma estuvo pensada sólo para la campaña 2016/17, ya que el gobierno confiaba en que habría una nueva Ley de Semillas para la campaña siguiente. Pero como esto no ocurrió, el sistema se extendió a la campaña $2017 / 18^{32}$. En un comunicado, Monsanto justifica esto en función de las patentes que ya tienen otorgadas para esta tecnología ${ }^{33}$.

\section{Resoluciones tendientes a modificar el uso propio}

Como analizamos en primer dispositivo, con la reforma en 1991 del Reglamento de la Ley de Semillas y Creaciones Fitogenéticano se modificaron las excepciones y, por lo tanto, las condiciones para el uso propio por parte de los agricultores se mantuvieron intactas. Sin embargo, esto llevó a algunos sectores a plantear que dicha ventaja no proveía una base jurídica suficientemente firme para precisar y hacer efectiva la protección de los derechos del obtentor.

En 1996 el INASE dictaminó la Resolución 35/1996, que consagra la normativa de la "excepción del agricultor". La resolución fue firmada por la presidenta del INASE, Adelaida Harries, una defensora de realizar reformas en la leyes de propiedad intelectual argentina para acercarlas a UPOV 91 (Filomeno, 2012).

Ésta se realizó con el fin de especificar restricciones sobre el derecho de los productores rurales para guardar semillas. La resolución busca aclarar las condiciones de la reserva en cuanto, entre otras, a la adquisición legal de la semilla originaria, individualización de la reserva, y destino de la semilla para la siembra por el agricultor en su propia explotación.

Un dato importante es que tiene lugar por primera vez en el derecho argentino la nominación excepción del agricultor, a la facultad del productor agropecuario de reservar semilla obtenida de la cosecha de una variedad protegida para su posterior siembra como semilla ${ }^{34}$.

Las críticas más fuertes vinieron de la mano de algunas de las organizaciones de productores rurales, que tomaron la medida como una respuesta del Estado a las demandas de las empresas de semillas, las cuales, como ya mencionamos, eran cada vez más exigentes al respecto. La Comisión Interna de Semillas de FAA, en un documento acordado en 2003, declaraba:

(...) se cuestionó la resolución 35/96 del Instituto Nacional de Semillas por cuanto su vigencia afecta a muchos productores -especialmente a los más chicos-, que no cuentan con la infraestructura necesaria para almacenar semilla y deben sí o sí 
sacarla de su campo para su adecuado acondicionamiento o depósito (...) esa resolución impone la necesidad de contar con la autorización del obtentor en un sinfín de situaciones que no se condicen con la real práctica agropecuaria. Y así, el chacarero queda acorralado por una normativa de un Estado que no parece situarse en el exacto punto medio de una relación de fuerzas sino inclinando el fiel de la balanza hacia una de las partes (FAA, 2005).

En este sentido, teniendo en cuenta los cuestionamientos de organizaciones de productores y expertos en propiedad intelectual, la resolución se aprobó pero prácticamente nunca tuvo efectos prácticos (Casella, 2005).

Años más tarde, y en medio de las primeras discusiones acerca de la modificación de la Ley de Semillas, la SAGPyA y el INASE continuaron emitiendo nuevas normas en un intento de reducir el nivel de lo que consideran una "piratería de semillas". Con ese objetivo, la Secretaría de Agricultura de la Nación publicó en el Boletín Oficial del lunes 21 de julio de 2003 la Resolución 52/03. La misma establece la obligatoriedad para que los productores comuniquen la cantidad por variedad de semillas utilizadas y a utilizar en sus establecimientos. Según la nueva resolución, los productores de trigo, soja y algodón deben presentar junto a la declaración de cantidades de semillas la documentación que acredite las operaciones de compra del insumo. Cabe aclarar que en caso de tratarse de semillas de uso propio, el productor deberá acreditar de igual forma la adquisición de la semilla que originó la multiplicación efectuada en su campo.

El interés por controlar el uso propio de semilla de las variedades mencionadas se presenta fundamentado en el hecho de que las mismas registran los índices más elevados de "bolsa blanca" al tratarse de variedades autógamas. Como vemos, la Resolución establece un sutil mecanismo de vinculación entre la utilización de la semillas para el uso propio por el agricultor (que no se dedica a comercializarla), con la proliferación del comercio de semilla ilegal (Díaz Ronner, 2013). En este sentido, la FAA elevó una voz crítica, que quedó plasmada en el Periódico La Tierra:

La Resolución 52/2003, en sus fundamentos, es coincidente con lo que expresan los sectores privados de la industria semillera y de las empresas multinacionales y se circunscribe dentro de los planteos de limitar el derecho del agricultor al uso de semilla propia para la siembra. La finalidad de esta normativa se inscribe dentro de las presiones por el cobro de regalías en caso de permitirse reservar semilla (...) Esta normativa constituye un apriete al productor, ya que se lo hace único responsable de los desaguisados del Estado Nacional en la materia. Nada se habla de la responsabilidad de las empresas semilleras, cuando se sabe que existe un gran desfasaje entre la superficie inscripta como lotes para producir semilla original, la necesidad real y los rótulos pedidos, lo que sugiere el origen de muchas "bolsas blancas" (...) (FAA, 2005).

Para seguir con los intentos por reglamentar el uso propio, la SAGPyA publicó en el Boletín oficial del 23 de junio de 2006 la Resolución 338/2006. La misma tenía como objetivo precisar los alcances cuantitativos (límites en la superficie y cantidad de semillas) de la denominada excepción del agricultor.

Para Díaz Ronner (2013), el hecho de limitarse la superficie y la cantidad de semillas para ejercer el uso propio resulta inaceptable desde el punto de vista jurídico, dado que se está alterando el texto de la Ley de Semillas mediante una resolución de la SAGPyA, que es de rango menor. Y, al mismo tiempo, menoscaba el ejercicio de un derecho que está estipulado por ley.

Si bien la Resolución no entró en vigencia debido a una falta de acuerdo en la CONASE en torno a su aplicación, es posible advertir la persistencia en la limitación cuantitativa al ejercicio del uso propio. Dicha limitante volvió a aparecer como una discusión con los intentos por modificar la Ley de Semillas a partir de 2012.

\section{REFLEXIONES FINALES}

A lo largo de este artículo identificamos la presencia de cinco dispositivos de cercamiento jurídico de las semillas: 
1. La Ley de Semillas: es la articuladora del resto de los dispositivos, y por lo tanto esta presente en todos los períodos con gran intensidad, ya sea por su sanción en 1973, la modificación de su reglamento en 1991, o los diversos intentos de modificarla a partir del 2003.

2. La (no) patente de Monsanto: esta discusión arranca en 1995 con la modificación de la Ley de Patentes. Un año más tarde, Monsanto intentó patentar la soja en Argentina y su pedido fue denegado aludiendo justamente a dicha ley. Al día de la fecha, las semillas aún no pueden ser patentadas en este país. El debate ha tenido menos fuerza que el anterior, pero todo indica que se intensificará en los próximos tiempos.

3. Disputa por las regalías de la soja RR: este debate comenzó en el año 2000 cuando a Monsanto se le venció la patente del glifosato. Tuvo mucha intensidad hasta 2010, cuando la empresa perdió el jucio con el Estado argentino. Luego de eso, la estrategia de apriete viró hacia el dispositivo siguiente.

4. Contratos soja RR2 Intacta: se comenzaron a aplicar en el año 2012, cuando se aprobó dicha soja en la Argentina y la discusión, tanto en relación a su legalidad como a su legitimidad, aún sigue vigente.

5. Resoluciones tendientes a modificar el uso propio: si bien la primer resolución para "reglamentarlo" es de 1996, el debate en torno a la necesidad de acotarlo va a darse con mucha intensidad durante el último período (2003-2015). Y, como quedó evidenciado, es el eje central de las disputas.

Por lo tanto, si bien podemos identificar una proliferación y complejización de dispositivos, el cercamiento de las semillas no se dio de manera lineal. Cada uno de éstos estuvo atravesado por tensiones y conflictos, por avances y retrocesos. Muchas veces se trató de leyes, decretos o resoluciones que, si bien se sancionaron, no lograron aplicarse de la manera en que se pretendía, como las resoluciones que buscan "reglamentar" el uso propio de las semillas o los proyectos de cobro de regalías globales y extendidas. Muchas otras, como el caso de la modificación de la Ley de Semillas, la patente de Monsanto, o los contratos bilaterales de regalías extendidas por la soja Intacta RR2 Pro, constituyen debates aún abiertos. Por lo tanto, las semillas en Argentina son un elemento de importantes debates y múltiples disputas.

Con más de la mitad de su tierra cultivable sembrada con semillas transgénicas, Argentina se presenta como un lugar estratégico para analizar las controversias en torno a la apropiación de las semillas. Se trata de un debate que va mucho más allá que una discusión legal o una disyuntiva técnico productiva. En efecto, tiene que ver con discutir el modelo agrario y, por lo tanto, el proyecto de país.

\section{Entrevistas citadas}

Aldo Casella (2013) - Abogado especializado en propiedad intelectual en semillas y colaborador, a lo largo de varios periodos, de la Federación Agraria Argentina (FAA).

Marcelo Regúnaga (2013) - Secretario de Agricultura de Argentina en dos oportunidades entre 1990 y 1993 y en 2001, y Secretario de Industria, Comercio y Minería en 1996.

Carlos Vicente (2013) - Miembro de la ONG GRAIN (Genetic Resources Action International) y del sitio Web de Biodiversidadla. Integrante de la campaña "No a la nueva ley Monsanto de semillas en Argentina" (2013-2015).

\section{Legislación analizada}

Acuerdo sobre Aspectos de los Derechos de Propiedad Intelectual que afectan al Comercio (ADPIC) de la OMC. Firmado el 15 de abril de 1994.

Convenio internacional para la protección de las obtenciones vegetales (UPOV). Revisado el 19 de marzo 1991.

Convenio internacional para la protección de las obtenciones vegetales (UPOV). Revisado el 23 de octubre 1978. 
Ley de Patentes de invención y Modelos de Utilidad, modificada por Ley No 24572/96

Ley de Semillas y Creaciones fitogenéticas Na 20247 de 1973

Reglamento de la Ley de Semillas y Creaciones Fitogenéticas modificado por el decreto 2183/91

Resolución 35/96 (dictada por INASE)

Resolución 52/03 (dictada por Sagpya)

Resolución 338/06 (dictada por Sagpya).

\section{REFERENCIAS}

Arza, V. (2014). Modernización tecnológica en transgénicos como estrategia de negociación política de multinacionales. Realidad Económica, 288.

Bartra, A. (2008). El hombre de hierro. Los límites sociales y naturales del capital. México DF: Editorial Itaca.

Bergallo, P., y Ramón Michel, A. (2012). Entre lo global y lo local: La confrontación por un nuevo marco legislativo sobre patentes farmacéuticas en la Argentina de los años noventa, Revista Interior Flacso, 31.

Bianco, M. (2015). El valor de la semilla. Propiedad intelectual y acumulación capitalista. Revista de Ciencias Sociales, DS-FCS, 28(36), 37-54

Bonefeld, W. (2001). The permanence of primitive accumulation: commodity fetishism and social constitution, en The Commoner, 2, 1-15.

Campi, M. (2013). Tecnología y Desarrollo Agrario. En Anlló G., Bisang R. y Campi M. (Coord.), Claves para repensar el agro argentino. (pp. 97-152). Buenos Aires: EUDEBA.

Casella, A. (2005). Federación agraria profundiza en contenidos. En Un país que resigna soberanía. Patentamiento y regalias en semillas, 55-175. Buenos Aires: Editorial Federación Agraria Argentina.

Correa, C. (2004). Monsanto vs. Argentina. Le Monde Diplomatique, Edición Cono Sur, 82, 4-5.

Correa, C. (2009). Monsanto contra Argentina por la exportación de harina de soja a la UE En G. Tansey y T. Rajotte (eds.), El control futuro de los alimentos, 230-233, Madrid: Mundi-Prensa.

De Angelis, M. (2001). Marx and primitive accumulation: The continuous character of capital's enclosures. The Commoner, 2, 1-22.

Díaz Ronner, L. (2013). Biotecnología y propiedad intelectual. En Martínez Dougnac G. (Comp.), De especie exótica a monocultivo. Estudios sobre la expansión de la soja en Argentina, 65-112. Buenos Aires: Imago Mundi.

Díaz Rönner, L., y Folguera, G. (2017). Propiedad Intelectual y Nociones de Vida: relaciones, condiciones de posibilidad y desafíos. Revista Iberoamericana de Ciencia, Tecnología y Sociedad, vol.12 no.35, 11-38.

EDI (2016). ¿A dónde va la economía del gobierno de Macri? Buenos Aires: Fundación Rosa Luxemburgo con fondos del Ministerio Federal de Cooperación Económica y Desarrollo de Alemania (BMZ).

FAA (2005). Un pais que resigna soberania. Patentamiento y regalias en semillas. Buenos Aires: Editorial Federación Agraria Argentina.

Filomeno, F. (2012), The social basis of intellectual property regimes: biotechnology in South American soybean agriculture (Tesis presentada a la Universidad Johns Hopkins para el grado de doctor en Filosofía), Baltimore, Maryland.

GRAIN (2005). Leyes de semillas: imponiendo un apartheid agrícola. Revista Biodiversidad, sustento y cultura, 45

Gutiérrez, M. (1994). El debate y el impacto de los derechos de obtentor en lospaises en desarrollo, el caso argentino. Buenos Aires: IICA.

Harvey, D. (2004). El 'nuevo' imperialismo: acumulación por desposesión. En Socialist Register, 99-129. Buenos Aires: CLACSO.

Kloppenburg, J. (2005). First the seed: the political economy of plant biotechnology. 2. ${ }^{a}$ ed. Madison: University of Wisconsin Press 
López Monja, C.; Poth, C., y Perelmuter, T. (2010). El avance de la soja transgénica, iprogreso cientifico o mercantilización de la vida? Un análisis crítico a la biotecnología agraria en Argentina. Buenos Aires: Ediciones Centro Cultural de la Cooperación.

Martinolich, A. (2006). Derechos de propiedad intelectual en las obtenciones vegetales: el caso de la soja y el conflicto Monsanto - productores agropecuarios. Programa de formación, 1-46.

Marx, K. (2000) (1867). El capital: crítica de la economía política. México: Fondo de Cultura Económica.

Naturaleza de Derechos (2016).Juicio a Monsanto por la patente de semillas transgénicas en la Argentina llega a la Corte Suprema de Justicia de la Nación, recuperada de http://www.naturalezadederechos.org/amicus.htm

Pellegrini Pablo (2013). Transgénicos: ciencia, agricultura y controversias en la Argentina. Bernal: UNQ Editorial.

Perelman, M. (2001). The secret history of primitive accumulation and classical political economy, The commoner, 2, $1-21$.

Perelmuter, T. (2017). El rol de la propiedad intelectual en los actuales procesos de cercamientos. El caso de las semillas en la Argentina (1973 - 2015) (Tesis para optar por el título de Doctora en Ciencias Sociales), Facultad de Ciencias Sociales, UBA, Buenos Aires, Argentina.

Premici, S. (2010). Monsanto muerde la semilla. Página/12, https://www.pagina12.com.ar/diario/economia/2-149 007-2010-07-07.html

Roux, R. (2008). Marx y la cuestión del despojo, claves teóricas para iluminar un cambio de época. Revista Herramienta, $38,61-74$.

Shiva, V. (2003) (2000). Cosecha robada. El secuestro del suministro mundial de alimentos. Buenos Aires: Editorial Paidós.

Svampa, M. (2012). Consenso de los commodities, giro ecoterritorial y pensamiento crítico en América Latina, OSAL (Observatorio Social de América Latina), Año XIII, 32, 15-38

Teubal, M. (2006). Expansión del modelo sojero en la Argentina. De la producción de alimentos a los commodities. Revista Realidad Económica, 220, 71-96

Trivi, N. (2016). La Ley de semillas en Argentina: la disputa por el control y el futuro de la agricultura. Geopolitica(s) Revista de estudios sobre espacio y poder, Volumen 7, 57-75.

\section{Notas}

1 Un dato importante a destacar es que la producción académica en Argentina vinculada con la propiedad intelectual en semillas es visiblemente menor a la existente en algunos países, sobre todo en varios países de América Latina. Esto se modificó, en parte, en los últimos cinco años, cuando comenzó a discutirse con mayor intensidad la posibilidad de modificar la Ley de Semillas.

2 Originalmente, las diferencias entre éstas eran marcadas. Pero la importante ofensiva de los últimos años por profundizar los derechos de propiedad intelectual en el ámbito de la biodiversidad está llevando a una inclusión en el derecho de obtentor de elementos propios de las patentes.

3 Existe un debate intenso acerca de la denominación: se habla tanto de derecho de los agricultores, como de excepción o de privilegio. Diversos autores se ocupan de interpretar con distintos alcances y consecuencias jurídicas y sociales de cada uno de estos términos.

4 La Revolución Verde en Argentina se inició en 1957 con la creación del INTA pero se profundizó durante la dictadura militar (1976-1983), a partir de la consolidación del desarrollo de la industria privada de maquinaria agrícola y de semillas. En estos años, además, se introdujeron las semillas híbridas para la siembra, que se volvería masiva a principios de los 80. De esta manera, los componentes típicos de la Revolución Verde (híbridos, fertilización, riego, herbicidas, fungicidas, insecticidas, cosecha anticipada y secado artificial) se pusieron de manifiesto en la campaña 1978/79.

5 Nos referimos a la eliminación de retenciones (impuesto a la exportación) para los productos agropecuarios y la reducción de cinco puntos a la soja (pasó del $35 \%$ al $30 \%$ ), que generó una transferencia de recursos al sector más concentrado; al cambio del nombre del ministerio a Agroindustria, lo que marca cuál es la concepción que se tiene de la agricultura; la aprobación de seis nuevos transgénicos de soja y maíz (las empresas beneficiadas fueron Syngenta, Dow Agro Sciences, Pioneer y Monsanto); la desarticulación del área de agricultura familiar, parte del Ministerio de Agroindustria, entre otras. 
6 El control de la producción y reproducción de las semillas por parte del Estado comienza a transformarse con las últimas modificaciones sufridas por estas leyes donde las empresas cumplen un rol fundamental en este sentido.

7 En 1961 se firma en París el primer Acta del Convenio UPOV, que crea el Derecho de Obtentor (DOV) y, en 1970, en EEUU se promulga la Plant Variety Protection Act.

8 1935: Ley de Granos y Elevadores.

9 Es importante destacar que la Ley de Semillas se sancionó bajo el gobierno de Facto del Dr. Gral. Alejandro Lanusse,

10 Esto quedó reflejado en el artículo $1^{\circ}$, donde consta que la Ley de Semillas y Creaciones Fitogenéticas "(...) tiene por objeto promover una eficiente actividad de producción y comercialización de semillas, asegurar a los productores agrarios la identidad y calidad de la simiente que adquieren y proteger la propiedad de las creaciones Fitogenéticas" (El subrayado es nuestro).

11 Se trata de una Asociación que agrupa a 56 instituciones y empresas obtentoras que realizan investigación y desarrollo de especies vegetales.

12 Un elemento fundamental fue el reforzamiento del alcance del derecho, que se evidenció sobre todo en tres elementos. Por un lado, se incorporó la novedad a las condiciones para la obtención de un título de propiedad intelectual (DOV), que no existía previamente. Por otro lado, se añadió la duración de las variedades extranjeras. Finalmente, incorporó el ámbito de exclusividad, es decir, cuáles son los actos que están sujetos a autorización del obtentor. Tal como remarca Casella (2013), "si uno lee esos actos, salta a las claras que estarían más vinculados con UPOV 91 que con UPOV 78".

13 Los trámites para la adhesión se realizaron bajo la gestión de Regúnaga en la SAGPyA a partir de 1991, pero la finalización se realizó en 1994 bajo la gestión de Felipe Solá, quién estuvo entre 1993 y 1999 en dicha Secretaría.

14 Según el relato de Gutiérrez (1994), instituciones extranjeras como ASTA (American Seed Trading Association) y FASEMA (France Semence de Mals) ya para el momento de sanción del Reglamento 1978 visitaron la Argentina con el fin de interesarse por el régimen de Propiedad Intelectual que acababa de sancionarse.

15 Los trámites los inician el secretario de Agricultura, Ganadería y Pesca, Marcelo Regúnaga, junto a Adelaida Harries y Ordoñez del INASE.

16 Se entiende por bolsa blanca, a las semillas consideradas ilegales, en tanto no tienen rotulado.

17 INTA (Instituto Nacional de Tecnología Agropuecuaria); INASE (Instituto Nacional de Semillas); Ministerio de Agricultura, Ganadería y Pesca.

18 ASA (Asociación de Semilleros Argentinos); CASEM (Cámara Argentina de Semilleros Multiplicadores); AACREA (Asociación Argentina de Consorcios Regionales de Experimentación Agrícola); AAPRESID (Asociación de Productores de Siembra Directa).

19 FAA (federación Agraria Argentina); SRA (Sociedad Rural Argentina), Coninagro (Confederación Intercooperativa Agropecuaria Limitada) y CRA (Confederaciones Rurales Argentinas).

20 El nuevo texto tuvo la opinión favorable de parte de la industria semillera representados en ASA, de la Asociación de Productores de Siembra Directa (AAPRESID) y también de la Asociación Argentina de Consorcios Regionales de Experimentación Agrícola (AACREA), de la Sociedad Rural Argentina, de Confederaciones Rurales Argentinas (CRA) y de CONINAGRO, aunque estas últimas con algunas objeciones. La Federación Agraria, en cambio, formuló su rechazo y se retiró de la mesa de negociaciones.

21 Todas las negociaciones tendientes a la reforma de ley siempre se realizaron a puertas cerradas, en el marco del Ministerio de Agricultura. Los anteproyectos nunca fueron divulgados ni puestos a consideración oficialmente para el debate público, pero sí fueron filtrados y, por lo tanto, pudieron ser analizados.

22 Definidos como (...) agricultor a quien, a fin de mantener sostenible su explotación agrícola, requiere una excepción al alcance del Derecho del Obtentor establecida en el Artículo $32^{\circ}$ de la presente Ley. El INASE inscribirá de oficio como agricultores exceptuados en el Registro de Usuarios establecido en al Artículo $13^{\circ}$ de la presente Ley, a los agricultores inscriptos en el RENAF a la fecha de promulgación de la presente Ley (Anteproyecto, 2012, k).

23 El proyecto explicita que, tras la compra de la semilla, el productor deberá pagar un derecho a las empresas por las siguientes tres campañas si siembra por la misma superficie comprada. Al cuarto ciclo no deberá pagar más, salvo que haga una superficie mayor, con lo cual deberá abonar la diferencia. Además, contempla como agricultores exceptuados a los productores de agricultura familiar, pueblos originarios y quienes tengan una facturación anual menor a 1,8 millones de pesos (tres veces la categoría más alta del monotributo). No explicita cómo se determinará quiénes se encuentran dentro de cada categoría.

$24 \mathrm{Al}$ igual que el resto de los países de América Latina, Argentina comenzó a legislar en materia de patentes a partir del siglo XIX (Pérez Miranda, 2002). En 1864 promulgó la ley $N^{a}$ 111, la cual se mantuvo vigente y sin modificaciones durante 130 años. Fue sustituida recién en 1995 por la ley Na 24.481, modificada a los pocos meses por la ley Na 24.572 y reglamentada por el Decreto Na 260/96.

25 Es importante destacar que si bien Las plantas no pueden ser patentadas por esta ley, sí pueden ser protegidos los derechos del obtentor por vía de la Ley 20.247 - Semillas y Creaciones Fitogenéticas, tal como venimos analizando. 
26 En algunos casos, a los agricultores se les exige hasta un $25 \%$ de la cosecha en pago por el empleo que hacen de las semillas, a la vez que se les impone el uso del herbicida producido por la misma firma (Casella, 2005).

27 El modelo se expandió hacia Río Grande do Sul a mediados de los noventa, cuando la soja RR fue introducida de manera ilegal por productores brasileños. Si bien el Poder Judicial Federal Brasileño aceptó una medida cautelar presentada por asociaciones de protección al consumidor y movimientos ecologistas, las presiones de Monsanto y las dimensiones alcanzadas por el cultivo arrastraron en 2003 al gobierno de Ignacio Lula Da Silva a aprobar su comercialización durante dos años.

28 Según constaba en el proyecto, el objetivo era lograr un sistema más equitativo que permita satisfacer los intereses de los obtentores de variedades vegetales mejoradas y de los productores agropecuarios en su conjunto. Este sistema permitiría cumplir más acabadamente con los objetivos de la Ley 20.247 (Ley de Semillas), esto es, promover una eficiente actividad de producción y comercialización de semillas, asegurar a los productores agropecuarios la identidad y calidad de la semilla que adquieren, y proteger la propiedad de las creaciones fitogenéticas.

29 El Centro de Estudios Legales del Medio Ambiente (CELMA) denunció ante la Justicia Federal que es "irregular" la forma en que fue aprobada la nueva estrella del agro, la semilla de soja Intacta RR2, de la empresa Monsanto. http://w ww.pagina12.com.ar/diario/sociedad/3-228335-2013-09-05.html

30 La Mesa de Enlace estuvo compuesta por la Sociedad Rural Argentina (SRA), Confederaciones Rurales Argentinas (CRA) y Confederación Intercooperativa Agropecuaria (CONINAGRO) y la Federación Agraria Argentina (FAA). Surgió en 2008, en el contexto del denominado "Conflicto del Campo", que se estructuró en torno a la Resolución n 125/2008 durante presidencia de Cristina Fernández de Kirchner, que establecía un sistema móvil para las retenciones impositivas a la soja, el trigo y el maíz.

31 "Para la cosecha de soja Campaña 2015/16, le serán extraídas al productor o remitente muestras de grano en el primer punto de entrega las cuales podrán ser requeridas por el Instituto Nacional de Semillas, organismo descentralizado en la órbita del Ministerio de Agroindustria, para la verificación del cumplimiento de la Ley de Semillas y Creaciones Fitogenéticas $N^{\circ} 20.247$ (ley de semillas)", dice el primer artículo de la resolución 207.

32 Para ampliar la información ver: http://www.bolsatech.com.ar/

33 Se trata de la patente AR026994B1 ("Nuevas construcciones expresadas en plantas y método para expresar una secuencia de ADN en las plantas") y la patente AR010897B1 ("Método para controlar la infestación de una planta de soja por un insecto de Tortricidae la familia").

Comunicado completo: http://www.monsantoglobal.com/global/ar/noticias-y-opiniones/Pages/ PRODUCTORES_CONTINUAR

\%C3\%81N_TENIENDO_ACCESO_A_LA_SOJA_INTACTA_RR2_PRO.aspx

34 Como veremos más adelante, si bien la Ley y el reglamento hacen referencia al uso propio, no refieren a la idea de excepción del agricultor. 